\title{
Las ONG y la cultura de la solidaridad: la ética mínima de la acción humanitaria
}

\author{
Joan Picas Contreras \\ Universitat de Barcelona. Departament d'Antropologia Cultural \\ Baldiri Reixac, s/n. 08028 Barcelona \\ jpicas@arrakis.es
}

\section{Resumen}

En los últimos años, las ONG han alcanzado enormes cotas de popularidad. Sin duda ha contribuido a ello la difusión, por los medios de comunicación de masas, de algunas catástrofes que han castigado a diversas poblaciones del planeta (léase —en orden cronológico- Etiopía, Somalia, Ruanda o los desastres ocasionados por el huracán Mitch en Centroamérica), que han causado un considerable impacto en la opinión pública. Corriendo un tupido velo sobre la eficacia de la ayuda que se presta y sobre sus consecuencias, la acción humanitaria, desplazándose del ámbito originario de los imperativos éticos, ha pasado a formar parte de lo que se considera políticamente correcto.

En este artículo se resitúa el significado de la solidaridad en los parámetros de la posmodernidad para llegar a la conclusión de que ésta se plantea no ya en términos de deber, sino de deseo; y, asimismo, de que el humanitarismo está más imbuido por una ética de la compasión que por una auténtica ética de la justicia. El perfil ético de la acción humanitaria se completa con una reflexión acerca de las condiciones que otorgan legitimidad moral a la ayuda, lo que obliga a abordar el asunto siempre controvertido del derecho de injerencia. La jerarquización de las actuaciones en función de elementos ajenos a la naturaleza del sufrimiento del prójimo lleva a pensar que la moral de la urgencia no es más que una moral de la preferencia.

Palabras clave: ONG, solidaridad, ayuda humanitaria, ética.

\section{Abstract. NGO and solidarity culture: the minimal ethics of humanitarian action}

In the last years, NGO's have reached enormous levels of popularity. Certainly, the diffusion by mass media of some catastrophes punishing diverse populations of the planet (that is - in chronological order - Ethiopia, Somalia, Rwanda or the disasters caused by hurricane Mitch in Central America) and its considerable impact in the public opinion have meant a big contribution to it. Drawing a discreet veil over the effectiveness of the aid and its consequences, the humanitarian action has shifted from the original scope of the ethical considerations to the sphere of the politically correct affairs.

In this paper, the meaning of solidarity is reconsidered under the parameters of postmodernity. The conclusion is that solidarity has left to be posed in terms of duty, and now is a question of desire; and, also, that humanitarianism is more imbued with an ethics of compassion than an authentic ethics of justice. The ethical profile of the humanitarian action is completed with a reflection about the conditions that grant moral legitimacy to the aid, which takes us to undertake the always controversial subject of the interference 
right. The hierarchical ordering of performances according to considerations beyond the nature of people's suffering leads us to think that the moral of the urgency is no more than a moral of the preference.

Key words: NGO, solidarity, humanitarian aid, ethics.

\section{Sumario}

El significado de la solidaridad Bibliografía

Ayuda humanitaria

y derecho de injerencia

De un tiempo a esta parte, la acción humanitaria y la cooperación para el desarrollo se han puesto de moda en todos los países de Occidente, también en España $^{1}$. Si hay un rasgo novedoso que sirva para caracterizar el pensamiento cívico-social de estos últimos años es lo que algunos llaman —adoptando la designación que identifica a distintas organizaciones humanitarias - "sinfronterismo", que sería algo así como un compromiso y un ejercicio cosmopolita de solidaridad que desarrolla la sociedad civil.

Pero el imperativo ético del «sinfronterismo» a menudo queda postergado por el imperativo de la acción, que valora más la intención que las consecuencias. La misma necesidad de actuar, el ritmo acelerado de la ayuda e incluso, en alguna medida, el pragmatismo de las acciones, transforman e hipotecan el carácter de unas prácticas que no deberían ser en exclusiva humanitarias (salvación de vidas), ni sólo económicas (distribución de fondos), ni sólo asistenciales (educativas, sanitarias...), sino ante todo un ejercicio de justicia social. Asimismo, la instrumentación política y comercial de lo humanitario, la propia manipulación del mundo de los sentimientos y de las emociones que realizan unos medios de comunicación cuya conducta también se rige por la lógica mercantil o por la lógica política, así como otros condicionantes ajenos a lo que constituye la esencia de la cooperación, no sólo hacen dudar de la legitimidad ética de la cooperación para el desarrollo, sino que también dificultan el establecimiento de los límites precisos del campo de la solidaridad ${ }^{2}$.

1. El hecho de que la solidaridad esté de moda e incluso el hecho de que la gente pueda llegar a ser muy generosa y solidaria ante acontecimientos puntuales o situaciones de emergencia, no supone en ningún caso, tal como reflejan algunas encuestas, que éste sea un valor dominante en nuestra sociedad.

2. Es de destacar que el discurso de los valores adquiere vigor correlativamente al agotamiento de los grandes proyectos políticos (los valores se esgrimen como algo auténtico, incólume, opuesto a la presencia espúrea del Estado). Pero si la acción caritativa ha sustituido la labor social del Estado, lo humanitario — como apunta Bruckner (1995: 266) — corre el riego de prescribir la política a costa de ser manipulado por ésta. 
Para debatir la legitimidad ética de la cooperación es preciso, ante todo, dirigir la mirada a las actuaciones que se llevan a cabo y a las relaciones de interdependencia que generan. Pero no basta, en el calor del debate, analizar la pertinencia de estas actuaciones desde un punto de vista técnico, ni siquiera basta proponer — al modo, por ejemplo, de Crocker (1996) — una nueva ética del desarrollo superadora de la filantropía caritativa, que sitúa a la población ayudada en una posición pasiva ${ }^{3}$. Aunque en sentido estricto solidaridad y justicia — como apunta de Sebastián (1996: 24) — no son equivalentes (la primera sería "más profana y menos metafísica», a la par que "más atrevida y generosa» que la segunda), no obstante no debería ser posible entender el conjunto de prácticas solidarias que conforman la cooperación más que bajo el contenido preciso que proporciona una ética de la justicia que capacite, en los términos de una ética del cuidado, para afrontar y reparar las desigualdades entre los hombres.

\section{El significado de la solidaridad}

El sustantivo solidaridad deriva etimológicamente de la expresión latina solidarius, que designa un tipo especial de obligaciones jurídicas compartidas por una pluralidad de sujetos. Esta expresión, a su vez, tiene su origen en la locución in solidum, que significa literalmente «íntegramente».

Pero más allá de las reminiscencias jurídicas, el término de algún modo se relaciona, en la cultura griega, con el equilibrio y la armonía que debe existir entre el todo y las partes, entre el yo individual y el nosotros social unidos por el vínculo de la filía. En Aristóteles está presente un cierto tipo de solidaridad que sería equivalente a una amistad civica que no está ordenada únicamente para la vida en común, sino también para la realización de buenas acciones. Asimismo, en el mundo latino, Cicerón y Séneca se refieren a una sociabilidad natural entendida como una tendencia a la ayuda mutua en el marco de un uso común de los bienes. En otro sentido, los conceptos de pietas y humanitas, utilizados en la escolástica, pasarán a formar parte del pensamiento de la Iglesia bajo la forma de misericordia y de comunión universal con Dios.

3. Aunque los conceptos de solidaridad y de caridad sirvan para designar formas de acción filantrópica que Casado (1992: 65-71) califica como "heteroayuda» (esto es, donaciones de bienes o servicios o de esfuerzo personal sin contrapartida obligatoria) para distinguirlas de la «ayuda mutua» (cuyos beneficios revierten en los propios autores), el segundo término, que evoca una virtud teologal consistente en amar al prójimo por compasión y que ha acabado confundiéndose con la sopa boba que repartían en el pasado algunas órdenes religiosas a los indigentes, progresivamente ha perdido aceptación en detrimento del primero, que se juzga como su sustituto laico y un paso adelante en la conciencia de las gentes. Sin embargo, para Sánchez Ferlosio (1998), que analiza el espectro semántico de una y otra palabra, caridad ha conservado un carácter fraterno mucho más amplio (el propio término filantropía, que en su origen griego significa "amor al género humano", se ha homologado al de caridad). Así, observa que caridad admite perfectamente "caridad con el enemigo", mientras que «solidaridad con el enemigo» connota de inmediato felonía o traición. 
En la edad moderna, el Estado (el hecho de compartir la nacionalidad) y la interdependencia que genera la división del trabajo se convierten en el principal nexo de unión entre los ciudadanos, lo que supone la pérdida del vínculo social que nacía de una fraternidad fundada en un origen común y unas mismas creencias ${ }^{4}$. En este contexto, la solidaridad, cuando no aparece como una obligación impuesta, deviene una cuestión de simpatía, una opción ya no estrictamente necesaria, sino deseable. Mientras que la razón de Estado sitúa la solidaridad a nivel político (política social), junto al ejercicio de la práctica del poder, sin embargo la razón utópica, que también crece con la modernidad, deseará ampliar el horizonte de la fraternidad ofreciéndose a todos los hombres sin distinciones e introduciendo un componente liberador ${ }^{5}$.

Por otra parte, si la tradición filosófica aristotélica desconocía cualquier otra praxis que no fuera la acción teleológica de personas individuales, Kant plantea el primado de una razón práctica universal no sujeta a principios finalistas. Para él, la ética dicta la necesidad de actuar en función de una obligación que nace del derecho de los otros (este acto de simpatía con los seres humanos no está inducido por la conmiseración ante el dolor o el remordimiento por la crueldad, sino que es una respuesta personal al imperativo categórico).

Pese a que el universalismo ético, de honda raigambre kantiana, será puesto en tela de juicio en la posmodernidad desde los parámetros de un relativismo que propone su sustitución por las distintas concepciones y tradiciones morales propias de cada cultura, pocos discuten que existe una obligación natural (esto es, que nace de la propia condición humana) que exige contribuir al bienestar de los demás. De tal modo, se suele aceptar que sólo ofreciendo una respuesta desde una responsabilidad solidariamente asumida es posible solucionar los grandes problemas de desigualdad que hoy en día se plantean a la humanidad (Cortina, 1985; Apel, 1985) .

En el contexto de la ayuda al Tercer Mundo, el concepto de solidaridad, en teoría, surgiría como una categoría moral presidida por una lógica de equivalencia, que exige ordenar la sociedad equitativamente, y por un principio de

4. Durkheim (1893) argumentó que la «solidaridad mecánica», en la que la cohesión social se fundamentaba en la identificación común de los individuos, era gradualmente reemplazada por una «solidaridad orgánica», propia de la sociedad industrial y que obedecía a las necesidades de la división del trabajo, en la que la cohesión social se basaba en la interdependencia.

5. En el sentido de unidad en la acción reivindicativa, la noción de solidaridad aparece en Inglaterra a mediados del siglo XIX (derivando de la forma francesa solidarité, utilizada en la terminología legal a finales del siglo XVIII) al convertirse en un concepto central, relacionado con la idea de clase social, en el desarrollo del movimiento cartista y sindicalista (Castellanos, 1998: 97).

6. Para Apel, en tanto que los problemas que se plantean son de civilización y no de naturaleza técnica, es la razón práctica — y no la razón técnica - la que debe responsabilizarse del desafío pertrechándose en una ética universalmente válida (lo que no impide que los ideales concretos de vida de cada pueblo o cultura puedan resolverse desde las distintas concepciones morales). 
generosidad o gratuidad, que se inscribe en el ámbito de la ética social y que se expresa, a través de la acción, en una "adhesión a la causa de otros», entendiendo siempre que estos "otros" poseen mayores necesidades que quienes practican la solidaridad (Etxeberría, 1997: 248)

Algunos han llegado a relacionar - acaso con excesiva precipitación- el auge de las ONG con un nuevo resurgir de los valores morales tras un largo período de atonía materialista. Sea como sea, la solidaridad característica de la posmodernidad, de la que estas ONG son un paradigma, paradójicamente no se distingue por un refuerzo del deber. Apela a la responsabilidad, en ningún caso a la imposición imperativa ni, por supuesto, a obligaciones de contenido jurídico; tampoco se exigen sacrificios personales, ni consagrar la vida a fines superiores a uno mismo, ni ningún tipo de renuncia que no sea voluntariamente elegida.

Lipovetsky (1992: 209) detalla la situación del siguiente modo:

El principio de responsabilidad aparece como el alma misma de la cultura posmoralista. Si bien las llamadas a la responsabilidad no pueden separarse de la valoración de la idea de obligación moral, tienen la característica de no predicar en absoluto la inmolación de uno mismo en el altar de los ideales superiores: nuestra ética de la responsabilidad es una ética "razonable», animada no por el imperativo de abandono de los propios fines, sino por un esfuerzo de conciliación entre los valores y los intereses, entre el principio de los derechos del individuo y las presiones de la vida social, económica y científica. El objetivo no es otro que contrarrestar la expansión lógica individualista legitimando nuevas obligaciones colectivas.

La ética de la solidaridad, liberada del entorno religioso, no genera sentimientos de culpa; el altruismo deviene indoloro. Esta moral secularizada —apunta el propio Lipovetsky (op. cit.: 47) — acaba transformada en «consumo interactivo y festivo de buenos sentimientos", reciclada y convertida en una suerte de espectáculo (incluso el mal se espectaculariza) vehiculado por unos medios de comunicación que son la única ventana desde la que se ve y se explica el mundo y sus infortunios. Ellos, en su condición de creadores de opinión, orientan una moda de la generosidad que estimula una conciencia ética light, temporal y puntual que sólo se manifiesta ante las grandes adversidades humanas ${ }^{8}$. Cuanto más se debilita la fuerza del deber, con menos reparos consumimos solidaridad ${ }^{9}$.

7. De Sebastián (1996: 16-17) aclara que la solidaridad no sólo es un discurso o un sentimiento, sino también —y ante todo — una cualidad de la acción que, en cuanto tal, sólo en la misma acción puede realizarse.

8. Baudrillard (1978: 9-80) sugiere que el dominio de la simulación por parte de los medios de comunicación erosiona los referentes y lleva al colapso de aquellas polaridades discursivas que sostenían el significado: imaginario/real, subjetivo/objetivo, privado/público, vida/muerte.

9. Cada cual, según sus preferencias, puede participar sin esfuerzo en lo que Bruckner (1995: 261) califica como la "gran fiesta del corazón». El propio acto de consumo transforma al 
Para Lipovetsky (op. cit.: 138-139), la cultura mediática y hedonista de esta sociedad que define como del "postdeber» «ha permitido superar tanto la cultura del imperativo categórico como la del interés bien entendido». Desvaloriza el ideal de la abnegación, el espíritu de disciplina y, en cambio, anima la satisfacción de deseos inmediatos. La especulación alrededor del dilema puedo/no puedo (si puedo, entonces debo ayudarles) se atenúa y se plantea en términos de deseo. Entregarse al prójimo con devoción deja de ser un bien en sí mismo. Evidenciando el predominio del gesto externo sobre la virtud privada, de los hechos que pueden ser exhibidos, el humanismo sinfronterista no quiere a los hombres, sino que lo que desea es presencia pública para ocuparse de ellos. Como afirma Bruckner (1995: 260), «el filántropo moderno se transforma no en amigo de los pobres, sino en amigo de la pobreza» (a aquéllos, a lo sumo, se los compadece mientras sigan siendo desgraciados; pero a la que se rebelan se los teme). O, expresándolo con otras palabras, «en el indigente sólo se percibe al indigente, no al hombre» (Bruckner, op. cit.: 255) ${ }^{10}$. No existe aquí una identificación con el «otro» partiendo de lo que es, "otro-yo»: se confunde el ser con el tener. Como confirma Finkielkraut (1996: 125-126), la «predilección por los menesterosos anónimos es más fruto del principio de precaución que del arrebato fraternal. En el plano intelectual al menos, esta moral de la urgencia extrema es una moral del confort extremo».

En nuestra sociedad —enseña Rorty (1989: 210) — no hay espacio para una solidaridad que se legitime en grandes teorías metafísicas, que se apoye en el reconocimiento de un yo nuclear - la esencia humana- compartido por todos los seres humanos (por otra parte, ello tampoco debería ser en sí mismo deseable, ya que la idea de un componente humano central y universal podría, a su juicio, restar libertad al individuo). La solidaridad, como la conciencia, es

ciudadano en mecenas (basta tomar una taza de "café solidario», pagar con una tarjeta de crédito de una entidad financiera que destine algún porcentaje del valor de la compra a subvencionar a una ONG o asistir a un concierto de rock contra el hambre en el mundo). La solidaridad no sólo adopta formas indoloras, sino también lúdicas: el agente moral se compromete en favor de una buena causa al tiempo que se lo pasa bien. La caridad se convierte en diversión; el dolor ajeno deviene espectáculo (reality show). En las llamadas «maratones televisivas» destinadas a recaudar fondos, que combinan generosidad, aires de festival y marketing, las donaciones se contabilizan y se baten récords como si se tratara de emular una gesta deportiva.

10. Puesto que una solidaridad con una humanidad anónima o, por analogía, un humanismo sin hombre genera una fidelidad puramente rutinaria (se apoyan con igual entusiasmo las causas más dispares: tibetanos, somalíes, hutus, bosnios, kurdos o kosovares van ocupando sucesivamente la categoría de víctimas merecedoras de nuestro interés, quedando descartadas otras de forma arbitraria) que corre el riego de consumirse, Bruckner (ibídem) acaba constatando que la generosidad, para reafirmarse, necesita «[d] evolver a los menesterosos una identidad y un rostro humano, [seleccionar] entre la masa de los desheredados unos cuantos ejemplares representativos. De este modo la estrella (o el benefactor) presta su nombre a quien no lo tiene, obliga a las miradas a posarse sobre él». Las formas de apadrinamiento o cierto tipo de esponsorización, que identifican al beneficiario, sacan provecho de esta circunstancia. 
pura contingencia, está sujeta al tiempo y al azar. Pero, sin embargo, el individualismo extremo bajo el que se concibe el compromiso y la crítica de las ilusiones ideológicas del pasado pueden habernos llevado a aceptar una suerte de ética que, aunque visible, no deja tampoco de ser una ilusión ética. En dicho sentido, el alcance limitado de la solidaridad sinfronterista parece ser más el fruto de esta ética de mínimos que de una imposibilidad fáctica de llevarla a cabo.

Si el acto ético — como mantiene Bajtin $(1924)^{11}$ — tiene una naturaleza ontológica, entonces se puede coincidir con Bilbeny (1997: 41) en que a la «revolución en la ética» de la posmodernidad, que ha modificado el marco de las percepciones, los hábitos y las creencias que nos servían hasta hoy para hablar de moral, se le ha sumado la "crisis de la ética».

\section{Ayuda humanitaria y derecho de injerencia}

La ayuda humanitaria o de emergencia (a menudo ambos términos se solapan), en cuya gestión las ONG han adquirido un protagonismo destacado, es una respuesta urgente a una situación de catástrofe, a un desastre provocado por hecatombes naturales (sequías, inundaciones, ciclones...) o por acontecimientos singulares de raíz política o social (conflictos bélicos, desplazamiento de refugiados, desastres económicos...), cuyas consecuencias (hambre, epidemias, violencia...) suponen un riesgo grave para los seres humanos que las padecen ${ }^{12}$. Aunque la mayoría de los actores reconozca que ésta no debería separarse de la ayuda al desarrollo, las acciones a largo plazo quedan postergadas $^{13}$. La denuncia de las injusticias que están en el origen de la adversidad también se sitúa en un plano secundario. Sólo vale salvar vidas anónimas sin demoras: la misma acción monopoliza toda la moral. Como puntualiza Finkielkraut (1996: 122), no importa quién es el individuo que sufre, cuál es su razón de ser, los motivos de su persecución o de su agonía: sólo interesa salvarlo sin más.

11. Para Bajtin el acto ético, como mecanismo de constitución, afirmación y supervivencia del "yo» en su relación con el "otro», está basado en una idea de responsabilidad, ineludible para cada persona, que no es de naturaleza jurídica, sino ontológica, y que deriva de las formas con que se percibe el mundo a través de la relación con este "otro». Cada acto que se lleva a cabo cambia algo en la estructura del mundo, en la posición del «otro» y en nosotros mismos.

12. Cuando se habla de desastre cada vez hay mayor consenso en limitar las referencias a su condición de agente físico y en ponderar sus características sociales. A pesar de que en circunstancias puedan existir desastres producidos por elementos naturales que, al menos parcialmente, se desarrollan con independencia de la acción humana (los terremotos o los ciclones tienen un cierto componente de azar), sin embargo el daño que ocasionan se explica por la situación de precariedad en que viven las poblaciones afectadas (Quarantelli, 1998).

13. Para Mendiluce (1997: 173-176), «no se puede continuar con una división cada día más artificial, contradictoria e ineficaz, al tratar de clasificar nuestra acción entre emergencia y desarrollo». La propia actitud de muchas ONG, que «actúan o dan la imagen de bomberos apagaincendios», es en parte responsable del error. Como recuerda Kabunda (1999: 78), precisamente aquélla entra en funcionamiento cuando falla la ayuda al desarrollo. 
En esta línea, Domingo Moratalla (1997: 247) señala que el humanitarismo «más que una ética de la justicia, quiere poner en práctica una ética de la compasión, donde además de salvar la vida se busca evitar el dolor. Ante la imposibilidad de la justicia, no queda más remedio que la compasión». En efecto, el agente humanitario observa el sufrimiento que está al alcance de la vista, pero en general — sin apenas distanciarse de la posición adoptada históricamente por la Cruz Roja - rechaza ser beligerante, renuncia a distinguir entre lo que es un accidente y lo que supone una agresión e incluso, como se puso de manifiesto tras la crisis de Ruanda de 1994 , entre víctima y verdugo ${ }^{14}$. Todos los infortunados son considerados, sin matices, como seres objeto de conmiseración, incapaces de hacer frente por sí solos a sus problemas. De este modo, la ética minima de la acción humanitaria nos traslada a las puertas de una ética minima de la acción política.

La forma en que las instituciones humanitarias expresan la necesidad de ayuda es, en este sentido, suficientemente reveladora. Por ejemplo, desde Médicos Sin Fronteras, tal vez la entidad con la que mejor se asocia hoy en día, desde un punto de vista mediático, la "ayuda de emergencia», se nos presenta un panorama de catástrofe permanente extremadamente simplista, en el que dicha $\mathrm{ONG}$ - como se advierte en el siguiente fragmento publicitario, fechado en 1996 - patrimonializa la ética del compromiso y se ofrece como única esperanza de salvación:

Más de 50 millones de refugiados en todo el mundo lo han perdido todo huyendo de la guerra, la pobreza o la enfermedad. Nosotros les proporcionamos atención médica, vacunación, formación del personal local, nutrición, suministro de agua potable, saneamiento ambiental, etc.

En 1984 fue Etiopía. En el 91, Yugoslavia. Somalia en el 92. Ruanda en el 94. Y hoy la región de los Grandes Lagos (Zaire, Ruanda, Burundi), donde 1.200.000 refugiados y desplazados se enfrentan a la guerra, el hambre y la enfermedad. En los últimos años, en MSF hemos acumulado la experiencia necesaria para socorrer a las poblaciones en peligro en sólo 24 horas. Se encuentren donde se encuentren.

Los dramas se suceden unos a otros al ritmo de las noticias, a la velocidad de las imágenes que transmite la CNN (los medios de comunicación poseen la facultad tanto de crear como de desgastar el acontecimiento ${ }^{15}$. Del mismo

14. Basta recordar que las organizaciones humanitarias se hicieron cargo de la atención de campos de refugiados en el ex-Zaire controlados por las milicias hutu que habían perpetrado acciones genocidas y desde los que continuaban hostigando al enemigo. Éste y otros casos semejantes invitan a reflexionar entorno a las contradicciones en que incurre la asistencia humanitaria, enfrentada al peligro permanente de que sea aprovechada por una de las partes o por un gobierno autoritario para avivar un conflicto que se pretende apaciguar.

15. Benthall (1993: 26-29) llega al punto de afirmar que los desastres son, en buena medida, una construcción de los medios de comunicación, ya que sin ellos no serían conocidos y, por tanto, no existirían, salvo para las víctimas. La actuación de las propias organizaciones humanitarias está sujeta a las exigencias de los medios de comunicación (éstos inspiran las conductas 
modo, cada nueva cruzada relega al olvido a la anterior. Si la finalidad de la acción fuera en verdad salvar al mundo, nos hallaríamos ante una gesta heroica y extenuante. Pero el desfile vertiginoso de las catástrofes acaba atenuando no ya la atención que se les presta, sino también el propio grado de compromiso. En definitiva, el «relato moral» y el «relato político» —en palabras de Ignatieff (1998: 376) — acaban transformándose en «espectáculo humanitario».

Completar el perfil ético de la ayuda humanitaria obliga a reflexionar acerca de las condiciones que pueden hacer moralmente legítima la ayuda y, como consecuencia de ello, a debatir acerca de la legitimidad del derecho de injerencia, que Mendiluce (1997: 124) llega al extremo de definir «como la posibilidad o el deber de llegar al uso de la fuerza para defender el derecho a la asistencia y a la vida de las poblaciones en riesgo» ${ }^{16}$. Para Arteta (1999: 63-64), éste sería un derecho que "trata de reducir la alteridad entre los que prestan su ayuda y los que la reciben, que resulta acentuada por su pertenencia a Estados diferentes».

El reconocimiento de que los derechos de las víctimas no pueden ser contingentes, es decir, sólo aceptables en función de determinadas circunstancias, aparece como el principal argumento justificativo del derecho de injerencia, que se impone como un imperativo. El discurso ético relativo a los derechos del hombre se invierte en discurso de las obligaciones humanas, entre las que está la de socorrer a las poblaciones en peligro. Así, el propio Kouchner (1991) reclama que las instituciones internacionales, asistidas de un «derecho de injerencia» indiscutible, tienen que asumirlo como deber ("deber de injerencia»). De tal modo, trabajar en nombre y en favor de las víctimas justifica la transgresión de aquellas reglas que impiden que se pueda actuar libremente. No obstante, y puesto que a pesar de todo la acción humanitaria, a nivel práctico, halla límites en el imperio de la ley (prohibición explícita de violar las fronteras de los estados) ${ }^{17}$, de hecho no sería adecuado referirse, en propiedad, a

a seguir y, a su vez, obligan a las organizaciones a adoptar estrategias que les permitan tener presencia en ellos). De un modo paralelo, Kouchner (1991: 194), fundador de Médecins Sans Frontières (MSF) y de Médecins du Monde, mantiene que «sin imagen no hay indignación: la desgracia sólo se abate sobre los desgraciados». Pero aún siendo cierta esta tesis, es indiscutible que la profusión de imágenes acaba provocándonos hastío y haciéndonos tolerar lo que en sí mismo es intolerable.

16. La autoría de la expresión «injerencia humanitaria» se atribuye por lo general a Kouchner, que la emplea en 1968 para vindicar la ayuda prestada por médicos franceses a las víctimas del conflicto bélico de Biafra. La resolución núm. 43/131 de la ONU, referida al Nuevo Orden Humanitario Internacional, que data de 1988, quiso trasladar la doctrina de la injerencia humanitaria al derecho internacional. Sin embargo, en la práctica el uso de la fuerza sigue recibiendo justificación cuando se producen amenazas para la paz y la seguridad internacional, pero no cuando existe sufrimiento de la población.

17. Rubio Llorente (1999) escribe que para justificar la legalidad del derecho de injerencia (violación de la soberanía de un país al no contar con el consentimiento del gobierno afectado) se aducen argumentos semejantes a los empleados por pensadores escolásticos como Suárez en relación con la "guerra justa». Pero la apelación a la vieja idea de la "causa justa» supone, de hecho, un abandono del Derecho (una vulneración de las normas que regulan 
criterios positivos que legitiman la ayuda, sino sólo a principios que permiten apreciar una intervención como no injusta.

En la injerencia humanitaria, sin embargo, se confunden otras consideraciones que trascienden en sentido estricto a la moral y se adentran en el terreno de lo sociológico. La negativa a condicionar el derecho de asistencia a las limitaciones que impone la soberanía nacional no es sólo el fruto de una reacción emocional, sino el resultado de transformaciones sociales profundas. En efecto, la contemporaneidad está marcada por procesos que afectan a la reorganización del tiempo y del espacio, vinculados a la expansión de lo que Giddens (1991: 10) denomina «mecanismos de desenclave» que "liberan las relaciones sociales de su fijación a unas circunstancias locales específicas, recombinándolas a lo largo de grandes distancias espaciotemporales», y bajo cuyos parámetros se concibe la globalización. Así, como advierte Mendiluce (1997: 122), la eliminación de barreras para el capital y para el comercio que resultan de dichos procesos de globalización demandan, a su vez, una universalización de los derechos humanos y «la creación de mecanismos, también universales, para imponer un orden internacional basado en su respeto y su defensa».

Abordando esta línea argumental, Naïr (1999) sugiere que tal vez no sea casual que la «ideología» del derecho a la injerencia «se haya labrado en los surcos del liberalismo económico mundial». Con ello da a entender no sólo que es un producto del sistema, sino también que sirve al objetivo de corregir algunas de sus disfunciones (lo humanitario ocupa el lugar de lo político cuando se trata de paliar los efectos más irritantes de la pobreza que produce el mismo desarrollo a través del mercado). Aceptando este punto de vista, llegaríamos a la conclusión de que las propias ONG, voluntariamente o no, contribuyen a consolidar las políticas neoliberales a través de su actividad asistencial.

Si la ayuda al desarrollo en general está condicionada económica y políticamente, aún con más motivo lo está la ayuda humanitaria, que es necesariamente unilateral y no admite corresponsabilización. Para los estados, a menudo los refugiados o los damnificados no pasan de ser piezas que se mueven en el tablero de la geopolítica, y, para las organizaciones humanitarias, un pretexto utilizado para tomar posiciones en un "mercado del dolor» que moviliza ingentes recursos.

Aun cuando la ayuda humanitaria profese indiferencia por las víctimas (la solidaridad, como se ha escrito, se practica con una humanidad anónima, lo que permite defender todas las causas), la capacidad de respuesta siempre es limitada y, por consiguiente, discriminatoria (en definitiva, ésta es una de las prerrogativas de la caridad). Cuando se decide intervenir en un lugar es a costa de otro, a pesar de que en todos los casos el sufrimiento sea semejante. Sólo una pequeña porción de las víctimas se transforma en beneficiaria. ¿Por qué

el derecho internacional) en favor de la especulación moral en la que imperan valores subjetivos. Hobbes ya puso de manifiesto que no hay nada tan subjetivo como la noción de justicia, que cada cual maneja a su antojo: a la postre, el contenido justo - $\mathrm{O}$ no injustode una causa lo determina la voluntad del poderoso. 
Ruanda y no Sierra Leone o Liberia, por qué Kosovo y no el Kurdistán? Sin duda, las obligaciones que genera el prójimo se jerarquizan en función de elementos ajenos al mismo, a la naturaleza de su sufrimiento. Esta constatación lleva a Bruckner (1995: 270) a mantener que la «moral de la urgencia» en realidad no es más que una "moral de la preferencia». Por ello, concluye preguntándose si acaso no sería más apropiado definir el derecho de injerencia como el «derecho a descuidar a algunos pueblos fingiendo prestarles auxilio» (op. cit.: 273).

\section{Bibliografía}

APEL, K. O. (1985). «Epílogo: ¿Límites de la ética discursiva?». En CORTINA, A. Razón comunicativa y responsabilidad solidaria. Salamanca: Sígueme, 1988, p. 233-262. ARTeTA, A. (1999). «La conciencia humanitaria». En MÉdicos SIN FronTERAS (ed.). El laberinto humanitario. Madrid: Acento, p. 32-67.

BajTin, M. M. (1924). Hacia una filosofía del acto ético: de los borradores y otros escritos. Barcelona: Anthropos, 1997.

BAUdRILlard, J. (1978). Cultura y simulacro. Barcelona: Kairós, 1998.

Benthall, J. (1993). Disasters, Relief and the Media. Londres: I.B. Tauris.

BILBENY, N. (1997). La revolución en la ética: hábitos y creencias en la sociedad digital. Barcelona: Anagrama.

BRUCKNER, P. (1995). La tentación de la inocencia. Barcelona: Anagrama, 1996.

CASADO, D. (1992). «Estructuras generales de las organizaciones voluntarias en España». En CASADO, D. (comp.). Organizaciones voluntarias en España. Barcelona: Hacer, 1995, p. 13-110.

CASTEllanos, E. (1998). "Caritat versus solidaritat». Quaderns de l'Institut Català d'Antropologia, 12, p. 77-104.

Cortina, A. (1985). Razón comunicativa y responsabilidad solidaria. Salamanca: Sígueme, 1988.

Crocker, D. A. (1996). «Hunger, Capability, and Development». En Aiken, W.; Lafollette, H. (eds.). World Hunger and Morality. Londres: Prentice Hall, p. 211-230.

DOMINGO MORATAlla, A. (1997). Ética y voluntariado: una solidaridad sin fronteras. Madrid: PPC.

ETXEBERRIA, X. (1997). Ética de la diferencia: en el marco de la Antropología cultural. Bilbao: Universidad de Deusto.

FINKIELKRAUT, A. (1996). La humanidad perdida: ensayo sobre el siglo XX. Barcelona: Anagrama, 1998.

GIDDENS, A. (1991). Modernidad e identidad del yo: el yo y la sociedad en la época contemporánea. Barcelona: Península, 1997.

IGNATIEFF, M. (1998). "Les récits qui nous hantent: la télevision et l'aide humanitaire». En Moore, J. (dir.). Des choix difficiles: Les dilemmes moraux de l'humanitaire. París: Gallimard, 1999, p. 369-388.

KABUNDA, M. (1999). «Acciones humanitarias y ayuda al desarrollo: una visión crítica desde el Sur». En MÉdicos sin Fronteras (ed.). El laberinto humanitario. Madrid: Acento, p. 68-92.

Kouchner, B. (1991). Le malheur des autres. París: Odile Jacob. 
LipOVETSKY, G. (1992). El crepúsculo del deber: la ética indolora de los nuevos tiempos democráticos. Barcelona: Anagrama, 1996.

MeNDILUCE, J. M. (1997). Con rabia y esperanzas: retos y límites de la acción humanitaria. Barcelona: Planeta.

NAïr, S. (1999). «El continente olvidado». El País, 19-3-1999.

Quarentelli, E. L. (1998). What is a Disaster: Perspectives on the question. Londres: Routledge.

Rorty, R. (1989). Contingencia, ironía y solidaridad. Barcelona: Paidós, 1991.

Rubio Llorente, F. (1999). «La guerra justa en la sociedad global». El País, 30-3-1999.

SÁNCHEZ Ferlosio, R. (1998). "Cultura ¿para qué?». El Pais, 25-7-1998.

SEBASTIÁN, L. de (1996). La solidaridad: «Guardián de mi hermano». Barcelona: Ariel. 